\title{
Análise leucométrica em bovinos tuberculinizados e sua aplicação no monitoramento da leucose enzoótica em rebanhos do estado de Pernambuco
}

Luiz Carlos Fontes Baptista Filho*, Artur Cezar de Carvalho Fernandes, Tamyres Izarelly Barbosa da Silva, Taciana Rabelo Ramalho Ramos, Lúcio Esmeraldo Honório de Melo

Instituto Federal do Sertão Pernambucano (IF Sertão-PE), Santa Maria da Boa Vista, PE, Brasil

*Autor correspondente

e-mail: luizmedvet@hotmail.com

\section{Resumo}

A leucose enzoótica (LEB) e tuberculose bovina (TB) comprometem o estado imunitário dos rebanhos, especialmente pelo potencial imunodepressor do vírus da leucose bovina (VLB). Inúmeros fatores interferem nos valores leucométricos dos bovinos, porém, pouco se sabe dos efeitos da TB sobre os mesmos. O objetivo do estudo foi avaliar o leucograma de bovinos tuberculizados, com vista ao uso da leucometria como ferramenta epidemiológica no combate à LEB em rebanhos leiteiros de Pernambuco. Amostras séricas de 1.000 bovinos procedentes de 33 rebanhos de diversos municípios do estado foram submetidas ao sorodiagnóstico da LEB (IDGA), sendo 920 bovinos previamente tuberculinizados pelo teste cervical comparado (TCC). Esfregaços sanguíneos foram confeccionados de todos os bovinos tuberculinizados, sendo a contagem total e diferencial dos leucócitos realizada usando técnicas convencionais. A avaliação da influência da TB no leucograma foi realizada pelo confronto dos resultados de quatro grupos experimentais, em função dos resultados da IDGA e TCC (grupo gTB - 41 positivos ao TSC; grupo gLEB - 151 positivos à IDGA; grupo gNEG - 379 negativos ao TCC e IDGA; grupo gINT - 43 positivos a ambos os testes). As taxas de prevalência da TB e da LEB foram, respectivamente, 11\% (99/920) e 28\% (282/1000), com 88\% (29/33) dos rebanhos contribuindo com ao menos um animal positivo para um ou ambos os testes. Dos 920 bovinos examinados, $43(4,7 \%)$ apresentaram positividade simultânea a ambos os testes. Os valores médios dos leucócitos e linfócitos (x $10^{3} / \mathrm{mm}^{3}$ de sangue) dos grupos experimentais foram, respectivamente: gTB $9,6 \pm 2,5$ e 5,9 \pm 1,9; gLEB 13,3 $\pm 6,3$ e 9,1 \pm 6,0; gNEG 11,5 $\pm 3,8$ e 7,6 $\pm 5,1$; e gINT 11,8 \pm 4,3 e 8,0 $\pm 3,5$. Houve diferença significativa $(P<0,05)$ entre os leucócitos e linfócitos, quando confrontados os grupos gTB (valores menores) e gLEB (valores maiores) com o grupo gNEG, enquanto o grupo gINT não diferiu $(\mathrm{P}>0,05)$ em nenhum dos parâmetros analisados em relação ao grupo gNEG. Conclui-se que o leucograma dos bovinos sofre influência da TB, devendo programas sanitários de combate à LEB em 
rebanhos leiteiros do estado de Pernambuco e que incluam a leucometria como ferramenta epidemiológica estratégica preconizar a prévia tuberculinização dos rebanhos envolvidos, sendo descartados os bovinos que apresentarem positividade ao teste imunoalérgico. 